\title{
ACTIVITIES OF SELF-REGULATED ORGANIZATIONS ON THE NASAMAR DESIGN SERVICES MARKET
}

\author{
(C) 2020 Grankina Svetlana Valeryevna \\ Assistant Professor \\ Samara State University of Economics \\ E-mail: svetav_grankina@mail.ru
}

Keywords: services, design services, self-regulatory organizations, design services market, construction market, urban space.

The article is devoted to the analysis of the activities of self-regulatory organizations in the Samara project services market. As a result of the study, the role of self-regulatory organizations is determined, which, along with other participants in the Samara market, play an active role in the formation of urban space.

УДК 331.2

Код РИНЦ 06.77.00

\section{РОЛЬ ЛЬГОТ В ПРИВЛЕЧЕНИИ, УДЕРЖАНИИ И МОТИВИРОВАНИИ ПЕРСОНАЛА}

\author{
(c) 2020 Гришина Валерия Александровна* \\ студент \\ (C) 2020 Зародина Алина Вадимовна* \\ студент \\ Самарский государственный экономический университет \\ E-mail: scorpiony70@mail.ru
}

Ключевые слова: привлечение персонала, удержание персонала, мотивирование персонала, льготы, государственные льготы, льготы организации для сотрудников, персонал, удовлетворенность персонала, социальная защита, социальная помощь, стимул.

В статье проанализированы характерные особенности процесса привлечения, удержания и мотивирования персонала, рассмотрены функции: привлечение, удержание и мотивирование персонала с позиции объекта и субъекта управления, проанализирована классификация стимулов, используемых в организации для сотрудников, описана классификация и специфические черты различных льгот, используемых в организациях для персонала. Рассмотрены льготы в федеральной сети японской кухни "Сушишоп".

В настоящее время перед организациями всех фрорм собственности вопрос привлечения, удержания и мотивирования персонала особенно актуален. Так как опытный, доцент.

* Научный руководитель - Богатырева Ирина Вячеславовна, кандидат экономических наук, 
квалифицированный и лояльный к организации сотрудник - фундамент эффективной работы любой организации, который позволяет быстро достигать цели деятельности. Однако среди множества существующих механизмов и способов привлечения, удержания и мотивирования персонала важно отобрать действительно работающие и важные для сотрудников.

Привлечение, удержание и мотивирование персонала - ключевые аспекты работы службы по управлению персоналом в организации, это связанная между собой работа, на выполнение которой необходимо направлять большое количество усилий и средств.

Привлечение, удержание и мотивирование персонала сопряжено с определенными функциями, направленными на достижение определенной цели, а именно:

- экономическая функция;

- социальная функция;

- адаптационная функция;

- управленческая функция.

При этом необходимо учитывать, что в настоящее время привлечение, удержание и мотивирование персонала- процесс взаимодействия работника и работодателя, поэтому данные функции, необходимо рассматривать с позиции объекта и субъекта управления (см. таблицу).

\section{Функции привлечение, удержание и мотивирование персонала'}

\begin{tabular}{|c|c|}
\hline Субъект (работодатель) & Объект (работник и его интересы) \\
\hline $\begin{array}{l}\text { Экономическая функция: повышение произ- } \\
\text { водительности труда и эффективности про- } \\
\text { изводства }\end{array}$ & $\begin{array}{l}\text { Экономическая функция: повышение уровня и } \\
\text { качества жизни, обеспечение воспроизводства } \\
\text { рабочей силы }\end{array}$ \\
\hline $\begin{array}{l}\text { Социальная функция: формирование опре- } \\
\text { деленного статуса, имиджа путем привлече- } \\
\text { ния к общественному производству }\end{array}$ & $\begin{array}{l}\text { Социальная функция: социальная стратификация } \\
\text { по уровню доходов в зависимости от качества и } \\
\text { количества труда }\end{array}$ \\
\hline $\begin{array}{l}\text { Адаптационная функция: приспособление } \\
\text { персонала к корпоративной культуре, усло- } \\
\text { виям достижения высокоэффективного труда }\end{array}$ & $\begin{array}{l}\text { Адаптационная функция: адаптация методов и } \\
\text { инструментов кадрового менеджмента ценностям, } \\
\text { ориентациям и стремлениям персонала }\end{array}$ \\
\hline $\begin{array}{l}\text { Управленческая функция: управление трудо- } \\
\text { вым поведением работника в соответстсвии } \\
\text { с миссией, стратегией, целями организации }\end{array}$ & $\begin{array}{l}\text { Управленческая функция: формирование обратной } \\
\text { связи как отклика об удовлетворенности предо- } \\
\text { ставляемыми благами }\end{array}$ \\
\hline
\end{tabular}

Таким образом, функции привлечения, удержания и мотивирования персонала отличаются в зависимости от субъекта или объекта управления. При этом цель мотивирования - корректировка поведения сотрудников и побуждение к выполнению определенных действий с помощью удовлетворения его потребностей и реализации его интересов.

Главная цель в дальнейшем удовлетворенность работника, которая включает несколько аспектов:

- удовлетворенность к трудовой деятельности;

- удовлетворенность в целом самой организацией;

- удовлетворенность отношениях с руководством в данной организации. 
Удовлетворенность сотрудника - это главный показатель, который необходимо учитывать работодателю, формируя такие условия, в которых сотруднику будет комфортно находиться со всех сторон его потребностей, в отношении к занимаемой должности².

Необходимо учитывать, что у каждого сотрудника организации существуют индивидуальные потребности, цели, приоритеты.

Наиболее популярными методами материального стимулирования в настоящее время являются:

- премирование сотрудников (за выполнение конкретных показателей),

- вознаграждение по итогам работы за определенный период,

- единовременное премирование (за выполнение важных заданий)3.

Главная цель системы премирования - повышение итогов работы деятельности компании. Необходимо подчеркнуть, что в настоящее время система премирования может устанавливать систему показателей премирования, санкционирующую мотивировать сотрудников перевыполнять плановые значения показателей премирования. Поэтому, создание действенной системы условий премирования в соответствии с определенными целями предприятия позволяет обеспечивать ей получение необходимой прибыли и достижение иных важных целей.

Кроме денежных стимулов, популярны и другие, которые представляют материальную ценность, но фактически представлены в виде льгот, которые могут быть гарантированы как государством, там и организацией. Льготы, гарантированные государством, являются обязательными, несут в себе не стимулирующую функцию, а роль гарантий и защиты сотрудников (ежегодный оплачиваемый отпуск, оплачиваемый больничный лист и др).

Зачастую неденежные стимулы для сотрудников наиболее актуальны. Независимо от того, какая заработная плата, сотрудники через какое-то время уже не удовлетворены. Используя данные методы, организация, таким образом решает индивидуальные проблемы сотрудников, косвенно повышая их доход.

Для привлечения, удержания и мотивирования персонала организация может использовать индивидуальные льготы для сотрудников. Это достигается путем соответствия целей сотрудников и целей организации, социальной защиты персонала, формирования благоприятного климата в коллективах. Комплекс льгот, которые могут быть предоставлены организацией сотрудникам представлены на рисунке.

Несмотря на важность использования льгот в организациях, далеко не все используют данный инструмент. Согласно опросу организаций, проведенного HR-журналом,

- лишь 19 \% организаций внедрили, или планируют в ближайшее время внедрение льгот для поддержания сотрудников и членов их семей;

- 43 \% организаций используют льготы периодически в зависимости от таких факторов, как успешное окончание года, финансовая экономия средств организации и др.

- 38 \% организаций планируют внедрение льгот, но не работали еще над данным вопросом детально4.

В деятельности российских организаций, распространенными льготами для сотрудников являются льготы в питании, здоровье, отдыхе, образовании сотрудников и их детей 


\begin{tabular}{|c|c|}
\hline & Классификация льгот \\
\hline $\begin{array}{l}\text { Социальные } \\
\text { льготы } \\
\text { в денежном } \\
\text { выражении }\end{array}$ & $\begin{array}{l}\text { - право приобретения для сотрудников акций предприятия по сниженной } \\
\text { цене } \\
\text { - выплаты работникам к личным торжествам, } \\
\text { - предоставление руководителям и особо одаренным инженерно- } \\
\text { техническим работникам служебных автомобилей, персональных каби- } \\
\text { нетов и т.д. } \\
\text { - обеспечение сотрудников дополнительной пенсией по старости }\end{array}$ \\
\hline
\end{tabular}

\begin{tabular}{|l|l|}
\hline $\begin{array}{l}\text { Обеспечение со- } \\
\text { трудников допол- } \\
\text { нительной пенсией } \\
\text { по старости }\end{array}$ & $\begin{array}{l}\text { - организация питания сотрудников } \\
\text { - обеспечение жильем и льготами по его приобретению } \\
\text { - организация медицинской помощи } \\
\text { - социально-консультативная помощь }\end{array}$ \\
\hline
\end{tabular}

Предоставление сотрудникам права пользования учреждениями социальной сферы предприятия

- организация физических занятий

- организация медицинского обслуживания

Социальная помощь семье, организация досуга работников и членов их семей

\section{Puc. Классификация льгот, направленных на привлечение, удержание и мотивирование персонала}

Для более наглядного примера проведено исследование системы мотивации федеральной сети японской кухни "Сушишоп. Данная организация существует с 2011 года. На 1 марта 2020 года открыто более 250 магазинов по всей России. Данные цифры дают понять, что количество персонала в сети достаточно большое, на один магазин приходится в среднем 10 сотрудников, не включая управленческий аппарат. Система льгот в сети достаточно развита, но денежные стимулы строго индивидуальны для каждой должности. В одном магазине работают повара, администраторы и один управляющий.

Мотивация для администраторов - выполнение ежемесячного плана. При перевыполнении плана, администратор получает премию, рассчитывающуюся по конкретной формуле. Чем больше администратор предлагает гостям, тем выше ежедневная выручка, чем выше выручка, тем выше вероятность выполнения плана. Таким образом, администратор сам отслеживает свою премию, что мотивирует его к лучшей работе.

Мотивацией для поваров является выполнение всех требований отдела контроля качества. При соблюдении установленных норм повара получают ежемесячную премию в размере до 5000 рублей. Такая система мотивации полезна не только для сотрудников, но и для всей сети в целом, так как замотивированные повара добросовестно выполняют 
свою работу, соблюдают чистоту на рабочем месте и следят за качеством реализуемой продукции.

Рассмотрев системы денежной мотивации для обеих категорий работников магазина данной сети, можно увидеть прямую взаимосвязь между ними. Чем качественней продукция, что готовят повара, тем больше гостей, а, следовательно, выше выручка магазина, что нужно администраторам. Чем больше гостей в сети, тем больше работы у поваров, что важно отделу контроля качества.

Разумеется, в сети есть льготы общие для всех сотрудников. К таким льготам относится право приобретения сотрудникам продукции сети со скидками, организация питания сотрудников, выплаты работникам к личным торжествам, а также создание комфортных труда. Также, в конце каждого месяца управляющий выделяет лучших работников месяца на основе индивидуальных заслуг сотрудников. Для своих сотрудников сеть полностью открыта и старается оказывать помощь во всех ссрерах их жизни, что говорит низкая текучесть кадров. В одном из магазинов города Самары за три года рабочее место покинул только один администратор по личным причинам.

Исходя из этого, можно сделать вывод, что льготы оказывают существенное влияние на привлечение и удержание персонала. Льготы, предоставляемые в федеральной сети японской кухни "Сушишоп" учитывают потребности сотрудников и делают работу в данной компании максимально комфортной для персонала.

Таким образом, в зависимости от специфики организации, категории занятых сотрудников, организации важно уделять внимание формированию льгот для привлечения, удержания и мотивирования персонала. Это обусловлено изменением содержания самого труда, существенным повышением уровня образованности персонала. При этом важно внедрять льготы различного характера: долгосрочные и краткосрочные, материального и нематериального характера, направленные на сотрудника и членов его семьи и т.д.

Используя льготы, важно учитывать их актуальность в настоящее время, а также целевую группу сотрудников. Мотивирование сотрудников к качественному труду - это не только цель одной организации, но и основа экономического развития страны, так как итоги мотивирования труда возмещают производственные расходы компании, обеспечивает получение определенной прибыли и санкционируют оплачивать налоговые отчисления в бюджеты страны.

1 Кондратова И.Г. Анализ использования трудовых ресурсов как важнейшей части ресурсного потенциала организации // Экономический анализ: теория и практика. 2016. №1. С. 32-37.

2 Волгин Н.А. Стимулирование производительности труда. Брянск, 2016. С.54.

3 Ульянов С. С. Роль современных методов материального стимулирования персонала // Молодой ученый. 2019. №9. С. 153-155.

4 Кабирова С.3. Применение нестандартных методов мотивации для привлечения высококвалифицированной рабочей силы // Молодой ученый. 2018. №4. С. 46-51.

5 Нурхамитова Д. А. Привлечение и удержание персонала в современных условиях // Международный журнал прикладных наук и технологий "Integral". 2019. № 4. C.47-51. 


\title{
THE ROLE OF BENEFITS IN ATTRACTING, RETAINING AND MOTIVING PERSONNEL
}

\author{
(C) 2020 Grishina Valeria Alexandrovna \\ Student \\ (C) 2020 Zarodina Alina Vadimovna \\ Student \\ Samara State University of Economics \\ E-mail: scorpiony70@mail.ru
}

Keywords: staff attraction, staff retention, staff motivation, benefits, state benefits, organization benefits for employees, personnel, staff satisfaction, social protection, social assistance, incentive.

The article analyzes the characteristic features of the process of attracting, retaining and motivating personnel, considers the functions of attracting, retaining and motivating personnel from the perspective of the object and subject of management, analyzes the classification of incentives used in the organization for employees, describes the classification and specific features of various benefits used in organizations for staff. The benefits in the federal network of Japanese cuisine "Sushishop" are considered.

УДК 336.

Код РИНЦ 06.00.00

\section{СУЩНОСТЬ И ПРИНЦИПЫ БАНКОВСКОГО ПОТРЕБИТЕЛЬСКОГО КРЕДИТОВАНИЯ}

\author{
(C) 2020 Гусарова Дарья Дмитриевна \\ магистрант \\ (C) 2020 Вишневер Вадим Яковлевич \\ кандидат экономических наук, доцент \\ Самарский государственный экономический университет \\ E-mail: ab3535@mail.ru
}

Ключевые слова: банковский потребительский кредит, заемщик, кредитор, принципы банковского потребительского кредитования, коммерческий банк.

В статье рассмотрена сущность банковского потребительского кредита. Выявлены основные принципы банковского потребительского кредитования.

Современные нестабильные экономические условия поставили перед российским банковским сектором новые задачи в развитии рынка потребительского кредитования. Исследование накопленных в период кредитной экспансии рисков, высокого уровня просроченной задолженности по потребительским кредитам становится все более актуальным в связи с восстановлением роста данного сегмента финнансового рынка'. 